\title{
EL TRAJE VACÍO. ORIGEN, PERVIVENCIA Y EVOLUCIÓN DE UN MOTIVO EN LA POESÍA ESPAÑOLA DE VANGUARDIA: ULTRAÍSMO, CREACIONISMO Y SURREALISMO
}

MARÍA EMA LlORENTE

Facultad de Humanidades (UAEM)

\section{RESUMEN}

Este artículo se propone el estudio del motivo de la representación del hombre como traje vacío, que aparece de manera recurrente y significativa en la poesía española de la primera mitad del siglo Xx, en autores como Gerardo Diego, Pedro Salinas, Rafael Alberti, Federico García Lorca, Emilio Prados, Vicente Aleixandre y Luis Cernuda.

Durante este periodo, y en éstos y otros autores, el motivo atraviesa distintos movimientos literarios y distintas estéticas y va evolucionando y adaptándose a las exigencias y los postulados de cada uno de ellos, sin perder su significación básica original de falsedad, inautenticidad o superficialidad.

El trabajo consiste precisamente en el estudio de la evolución de este motivo, que, remontándose a la poesía barroca e incluso anterior, sigue estando vigente en la poesía española posterior al surrealismo.

Desde una valoración inicial del hombre vacío o cosificado, representado únicamente por la exterioridad de las ropas que viste, que se produce en la poesía ultraísta y creacionista, el motivo evoluciona hacia las connotaciones negativas que adquiere durante el surrealismo, que verá en esta imagen un signo de la enajenación del hombre y la sociedad contemporánea.

Esta visión crítica y negativa provocará que el motivo derive hacia la preferencia por el hombre natural, el hombre desnudo o el hombre animal de la última poesía surrealista y de la poesía social, en un proceso de vuelta a la humanización y un intento de recuperación de lo auténtico del hombre.

Palabras clave: Motivo, traje vacío, corazón, enajenación, poesía española

\section{THE EMPTY SUIT. ORIGIN, SURVIVAL AND EVOLUTION \\ OF A MOTIF IN THE AVANT-GARDE SPANISH POETRY: ULTRAISM, CREATIONISM AND SURREALISM}

\begin{abstract}
This article sets out the study of the motif of the representation of the man as an empty suit that appears in a significant way in the first half of the $20^{\text {th }}$ century in the Spanish poetry, in authors like Gerardo Diego, Pedro Salinas, Rafael Alberti, Federico García Lorca, Emilio Prados, Vicente Aleixandre and Luis Cernuda.
\end{abstract}


During this time, and not only in the above mentioned authors but in many others, the motif crosses different aesthetics and diverse literary movements, evolving and adapting to the exigencies of each of them, without losing its original basic meaning of falsification, lack of authenticity and superficiality.

The work consists of the study of the evolution of this motif that goes back to the Baroque poetry and even before and still is present in the Spanish poetry after surrealism.

From an initial valuation of the empty man, represented only by the external clothes that he wears, like in the ultraist and creationist poetry, the motif evolves towards the negative connotations that acquires during the surrealism, that views this image as a sign of the alienation of the man and the contemporary society.

This critical and negative vision would cause that the motif derives at the end towards the preference by the natural man, the naked man or the animal man of surrealistic and social poetry in a process of returning to humanization and in an attempt of recovery of the authentic being of the man.

Key words: Motif, empty suit, heart, alienation, Spanish poetry

Durante la primera mitad del siglo XX aparece en la poesía española -primero en el ultraísmo y el creacionismo, después en algunos miembros de la Generación del 27 y finalmente en el surrealismo y en poemas posterioresel motivo ${ }^{1}$ del cuerpo y del hombre como algo vacío, como una simple exterioridad sin contenido, reducida, la mayoría de las veces, al traje o al vestido exterior. Este motivo se repite de manera recurrente en diferentes autores y momentos literarios, dejando ver una determinada concepción del hombre, de su naturaleza y de sus relaciones con lo que le rodea, y va evolucionando en sus manifestaciones a medida que van evolucionando también la historia literaria y el concepto de literatura.

El objetivo de este trabajo será, por tanto, estudiar la aparición de este motivo en distintos autores - Gerardo Diego, Pedro Salinas, Emilio Prados, Rafael Alberti, Luis Cernuda y Federico García Lorca, entre otros-, y dar cuenta de su evolución o transformación a lo largo de la poesía española de la primera mitad del siglo XX. Lo que me interesa es, precisamente, señalar la pervivencia de un motivo a lo largo del tiempo y a través de distintos movimientos o momentos literarios, y observar, a través de este enfoque histórico o diacrónico y comparativo, cómo se transforma o se adapta este motivo al cambio de las sensibilidades y manifestaciones poéticas para, a pesar de estos cambios, adaptaciones y contactos con otros motivos de la época, continuar siendo expresivo y tener vigencia como motivo literario.

${ }^{1}$ Utilizo el término «motivo» con el significado general de elemento o unidad semántica breve, con cierta autonomía, que se repite en distintos autores y obras, y que puede aparecer en tiempos y espacios diferentes, manteniendo, a pesar de las variaciones y modificaciones, su núcleo significativo básico u original. En este sentido, sería comparable o semejante a otros términos similares como «tópico» o «imagen recurrente». Para éstas y otras cuestiones en relación con estos términos, véanse los estudios recogidos en NAUPERT, C. (comp.). Tematología y comparatismo literario. Madrid: Arco/Libros, 2003. 
En esta formulación del hombre o del cuerpo vacío, tan abundante en la poesía española de este periodo, confluyen distintas concepciones tanto filosóficas como antropológicas, culturales y literarias, concepciones que se materializan poéticamente en este motivo y que, a su vez, pueden servir para explicarlo y ayudar a su comprensión e interpretación.

Literariamente hablando, el motivo como tal parece remontarse a la poesía barroca, en su representación del hombre como templo vacío o cuerpo deshabitado. Así lo han indicado ya autores como Francisco Ruiz Soriano, que señala como antecedente de este motivo la poesía barroca de carácter metafísico de John Donne y de Quevedo², y María Clementa Millán, quien en su edición de Poeta en Nueva York, afirma también que esta imagen existe ya en la poesía barroca de Quevedo, de la que pasará después a la poesía española contemporánea ${ }^{3}$.

Pero, a pesar de que sea en la poesía barroca donde el motivo aparece delineado con más claridad, no puede dejarse de lado, como el mismo Francisco Ruiz Soriano señala, la existencia de una tradición cultural y literaria previa que, partiendo de la lírica cortés y religiosa y pasando por los poetas románticos, llega hasta Baudelaire y a los surrealistas franceses, así como a T. S. Eliot, cuya influencia será fundamental para algunos autores españoles ${ }^{4}$.

Además de la existencia de esta trayectoria literaria, el motivo del hombre como cuerpo o traje vacío se sustenta, como ya mencioné, sobre algunos presupuestos filosóficos y antropológicos, entre los que se encuentra la concepción del hombre como un ser dual, compuesto de exterior e interior, alma

\footnotetext{
${ }^{2}$ RUIZ SORIANO, F. «Eliot, Cernuda y Alberti: la ciudad vacía». Cuadernos Hispanoamericanos, 1995, $\mathrm{n}^{\circ}$ 539-540, p. 47.

${ }^{3}$ GARCÍA LORCA, F. Poeta en Nueva York. Millán, M. C. (ed.). Madrid: Cátedra, 1989, pp. 242-243. Coherente con la visión arquitectónica del Barroco, Quevedo, entiende la vida como esencia dentro de un receptáculo, cuando afirma, por ejemplo, que vivir es pasar de la «cuna» a la «sepultura», o cuando define la vida como «prisión». Asimismo, la concepción barroca del hombre como ser marcado por la temporalidad y por la muerte, hacen a Quevedo elaborar y tratar a lo largo de toda su poesía «metafísica» el tópico de la muerte como algo cotidiano o diario, que ocurre a cada instante -el Cotidie morimur-, que convierte a la vida en muerte viva, «sepultada» en el cuerpo. Estas ideas de la vida fugitiva y de la muerte continua conducen, por tanto, a la reducción o a la aniquilación del hombre, que queda convertido así en vacío, hueco y nada. Por otro lado, en la poesía barroca en general es frecuente también la asociación o la representación del hombre como «templo», como ocurre, por ejemplo, en el poema de Góngora «De pura honestidad templo sagrado», en el que todos los rasgos de la mujer se armonizan dentro de un orden arquitectónico, no sólo para embellecerla, sino también para hacerla más grávida y persistente frente al paso del tiempo que se teme. Para una revisión de estas ideas véanse ALONSO, D.; LAÍN ENTRALGO, P. «Quevedo. Expresión y talante poético». En: Rico, Francisco (ed.). Historia y crítica de la literatura española, Siglos de Oro: Barroco. Barcelona: Ariel, 1983, pp. 593-603; y ROSALES, L. y OROZCO DÍAZ, E. «Quevedo. Temas y Tópicos». En: Rico, Francisco (ed.). Historia y crítica de la literatura española, Siglos de Oro: Barroco. Barcelona: Ariel, 1983, pp. 669-676.

${ }^{4}$ RUIZ SORIANO, F. Op. cit., pp. 46-47.
} 
y cuerpo, continente y contenido. Según esta oposición, lo exterior es lo material, lo carnal, lo corporal, mientras que lo interior es lo espiritual o lo esencial. Esta oposición se vuelve finalmente una valoración, puesto que lo que importa en el hombre, lo que se valora, no es lo exterior, sino lo interior, según una concepción general de esta dialéctica del continente y el contenido:

La cualidad profunda, el tesoro sustancial no es lo que encierra, sino lo encerrado. No es, en resumidas cuentas la cáscara lo que cuenta, sino la almendra. No es el frasco lo que importa, sino la embriaguez. (...). Porque la interioridad «superlativa» es lo que constituye la noción de sustancia ${ }^{5}$.

A esta concepción antropológica general, se le añade la valoración u oposición social autenticidad/apariencia, también distribuida, como señala Julius Evola, en términos de lo interior/exterior, y que resultará fundamental en la comprensión del motivo del cuerpo vacío y en su evolución:

(...) mostraremos que todo ser humano se compone de dos partes. Una es la parte esencial, y la otra es la parte exterior, artificial y adquirida que se forma en la vida social y que crea la «persona» del individuo: persona entendida aquí en el sentido original del término, que quería decir, como se sabe, «máscara», la máscara del actor (por oposición al «rostro», que por su parte cabe hacer corresponder a la parte esencial $)^{6}$.

Inserta en esta tradición cultural y de pensamiento, la poesía de principios de siglo XX se encuentra, además, con la necesidad estética y formal de romper con la producción poética anterior — Romanticismo y Modernismo- y con su excesiva tendencia a la sentimentalidad y a la expresión individual. Esta necesidad de ruptura con los caminos agotados anteriores lleva a desterrar del texto todo lo relacionado con el yo y con sus sentimientos, idea en la que juegan un papel fundamental las formulaciones de Stephan Mallarmé, adoptadas después también por Paul Valéry, en relación con la necesidad de separar lo personal de la obra de arte. El poeta debe desaparecer y ceder la iniciativa a las palabras. Estas mismas pautas de desterramiento del yo se encuentran igualmente, como señala B. Ciplijauskaité, en las proclamas futuristas, en la condena del «confesionalismo» por parte de los ultraístas, y en la teoría y la práctica de T. S. Eliot y James Joyce, y coinciden en el tiempo con la popularidad de las teorías de Freud en relación con los deseos velados, reprimidos o escondidos por imperativos culturales y sociales ${ }^{7}$.

En el caso concreto de España, estas reflexiones se relacionan además con un concepto como el de la deshumanización del arte, de José Ortega y Gas-

\footnotetext{
${ }^{5}$ DURAND, Gilbert. Las estructuras antropológicas de lo imaginario. Madrid: Taurus, 1982, p. 245.

${ }^{6}$ EVOLA. Julius. Metafísica del sexo. Palma de Mallorca: José de Olañeta, 1997, p. 49.

${ }^{7}$ CIPLIJAUSKAITÉ, Biruté. De signos y significaciones. I, Juegos con la Vanguardia: poetas del 27. Barcelona: Anthropos, 1999, p. 17.
} 
set, que ocasionará una amplia polémica entre los artistas y los intelectuales de este momento artístico y del posterior ${ }^{8}$. El concepto de deshumanización, unido a todo lo anterior, se acabará asociando, como intuye B. Ciplijauskaité, a la idea de despersonalización ${ }^{9}$. Es decir, para borrar el yo, el sentimentalismo y la emoción, que hacen el texto demasiado humano, se borra o se hace desaparecer a la persona misma, o al menos, se presentan unas personas incompletas, mutiladas e im-personales. Y como la humanidad reside básicamente, como señalan Durand y Evola, en el interior del hombre, ésta puede negarse o anularse mediante la negación de esa interioridad, reduciendo al hombre a su apariencia exterior o a su vestido, tal como muestran los numerosos textos poéticos que existen al respecto.

En la poesía ultraísta, primera manifestación poética de las vanguardias en España, confluyen dos factores que van a conducir a la formulación directa o explícita del motivo del hombre vacío de la poesía posterior, que son, por un lado, la prohibición tácita o la restricción de utilizar las palabras usadas durante el Romanticismo y el Modernismo para referirse al sentimiento y a la emoción —como, por ejemplo, corazón, alma, amor, etc.—; y por otro, la admiración y el gusto por el mundo de la tecnología y de la máquina adoptados del futurismo, que afecta a la forma en que se representa al hombre y a las relaciones humanas.

En esta primera vanguardia empiezan a aparecer poemas en los que los contenidos amorosos tradicionales, sin llegar a desaparecer del todo, se esconden o se disfrazan bajo la apariencia o el maquillaje vanguardista. Es decir, los temas humanos, personales y sentimentales se revisten de una ambientación y un léxico técnico y tecnológico, que saturan los poemas de palabras consideradas hasta la fecha como extra-poéticas o anti-poéticas. Aparecen así poemas amorosos ambientados, por ejemplo, en una sala de hospital, como el poema «Neumotórax», de Rogelio Buendía, con la consiguiente abundancia de palabras técnicas y médicas, como «manómetro», «nitrógeno», «pleura», etc., en el que la amada tradicional ha sido sustituida por una enferma tumbada, «con el costado/ perforado por la aguja» ${ }^{10}$.

\footnotetext{
${ }^{8} \mathrm{Si}$ en un primer momento se adoptan para la poesía y el arte en general los conceptos de poesía pura o poesía deshumanizada, esto será después motivo de crítica y de polémica para autores como Pablo Neruda, quien, en su viaje a Madrid, en el año 1934, publica los primeros números de su revista Caballo Verde para la poesía, en donde aparece el manifiesto «Por una poesía sin pureza». Este manifiesto supondrá una vuelta a una poesía «humana», corporal, orgánica, y de signo totalmente opuesto a la anterior. Para la revisión en profundidad de esta polémica véase CANO BALLESTA, José Luis. La poesía española entre pureza y revolución (1920-1936), Madrid: Siglo XXI, 1972.

${ }^{9}$ Así lo formula la autora explícitamente: «se podría tal vez conciliar la des-humanización que ve Ortega en el arte nuevo con la des-personalización que todos practican». CIPLIJAUSKAITÉ, Biruté. Op. cit., p. 17, nota 3.

${ }^{10}$ Publicado en 1920 en la revista Grecia y recogido en DÍEZ DE REVENGA, Francisco Javier. La poesía de vanguardia. Madrid: Ediciones del Laberinto, 2001, p. 68.
} 
Igualmente, en el poema ultraísta «Cines», de Lucía Sánchez Saornil, se representa una escena amorosa o sentimental entre una pareja, pero modernizada o disfrazada bajo la tecnología del mundo del cine, ámbito con el que la literatura y la vanguardia en general mantiene una estrecha relación en este momento $^{11}$. Los protagonistas ya no son los amantes de la poesía tradicional, sino que son actores anónimos de una realidad que, introducida por la ventana y reflejada en el espejo de la habitación, se cuestiona, en su calidad de presencia indirecta o duplicada, lo mismo que ocurre con el cine. En este contexto, estos dos amantes pierden parte de su apariencia humana, pues en su intercambio de palabras y miradas han quedado convertidos en proyector y pantalla respectivamente:

La ventana pantalla cinemática reproduce su película inmortal en los espejos.

La cinta se fragmenta a cada paso y se barajan los episodios.

Los actores son siempre distintos.

Tú y yo actores anónimos un día pasaremos ante el objetivo ...

A toda luz mis palabras reflectores proyectan en tus ojos un film sentimental ${ }^{12}$.

Y la misma relación «amorosa» pero reescrita a lo tecnológico o disfrazada de modernidad aparece en el poema «35 bujías», de un Pedro Salinas en sus inicios vanguardistas o ultraístas, en el que se poetiza la relación entre el hablante y una «amada eléctrica», princesa que está atrapada dentro de la bombilla, y que el amante libera al encender la luz ${ }^{13}$.

${ }^{11}$ En este sentido véase CARNERO, Guillermo. «El mito de la ciudad en la época vanguardista». En: Rovira, J. C.; Navarro, J. R. (eds.). Literatura y espacio urbano. Alicante: Caja de Ahorros del Mediterráneo, Fundación Cultural, 1994, pp. 84-93.

${ }^{12}$ DÍEZ DE REVENGA, F. J. Op. cit., p. 73.

13

Sí. Cuando quiera yo la soltaré. Está presa, aquí arriba, invisible.

Yo la veo en su claro castillo de cristal, y la vigilan

—cien mil lanzas - los rayos

— cien mil rayos- del sol. Pero de noche cerradas las ventanas para que no la vean - guiñadoras espías- las estrellas, 
Además de esta ambientación o esta reescritura a lo tecnológico como primer paso hacia la despersonalización, en la poesía ultraísta, así como en la creacionista posterior, se observa una tendencia hacia la desvalorización y ridiculización del corazón, en tanto órgano asociado comúnmente con los sentimientos amorosos y también en cuanto palabra abundantemente repetida en la poesía anterior. Este proceso de degradación se realiza, la mayoría de las veces, mediante la cosificación de este órgano, que aparece así asociado o comparado con objetos cotidianos y máquinas repetitivas, como el reloj, el termómetro, el ascensor, e incluso el grifo. Como explica Mario Hernández:

«Ascensor»y «grifo» introducían en escena objetos de interior doméstico, que resultaban prestigiados en oposición a los viejos símbolos naturales. Se producía, tácitamente, la irrupción del mundo mecánico que rodea al hombre de la civitas moderna (...). El mismo corazón había sido irónicamente degradado hasta mostrarlo convertido en un artilugio que poseía cuerda para poder funcionar, es decir, para poder generar el sentimiento poético ${ }^{14}$.

En los poemas de Gerardo Diego de Imagen (1922) y Manual de espumas (1924), es frecuente encontrar afirmaciones como: «Pobre corazón mío/ Hoy no le he dado cuerda» ${ }^{15}$, o: «Mi corazón y el baño se vacían ${ }^{16}$.

Paralelamente a este proceso de reificación o cosificación del órgano que representa lo humano por excelencia se produce el proceso inverso de animación o personificación de objetos externos al hombre; atributos y prendas de vestir como los guantes, el pañuelo, el chaleco, etc., comienzan a utilizarse para designar, metonímica o sinecdóquicamente al hombre entero, y adquieren rasgos y cualidades humanas. De esta forma, la responsabilidad emocional, por así decirlo, se ha desplazado del hombre a sus atributos, en un pro-

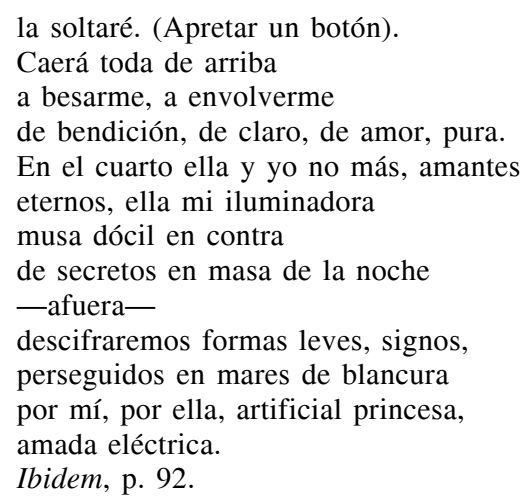

${ }^{14}$ HERNÁNDEZ, Mario. «Imagen en Cometa errante». Anales de Filología Hispánica, 1989, n 8, p. 49.

${ }^{15}$ DIEGO, Gerardo. «Carnaval». En: Obra completa. Poesía I y II. Díez de Revenga, F. J. (ed.). Madrid: Aguilar, 1989, I, p. 117.

${ }^{16}$ DIEGO, Gerardo. «Fuente». En: Op. cit., I, p. 171. 
ceso de proyección o exteriorización, puesto que los que realizan las acciones amorosas en estos poemas son ahora los objetos y las prendas de vestir. Nuevamente, en Gerardo Diego aparecen imágenes como: «Mi americana intacta no ha visto los amores $»^{17}$, «canta y canta y canta mi pañuelo» ${ }^{18}$, o «En todas partes te adivino y te llamo/ Mis tirantes te buscan te adoran mis pijamas» ${ }^{19}$. La cosificación del hombre implica, así, en estos casos, una personificación de sus ropas, que tiene que ver, por un lado, con un procedimiento general de animación de lo inanimado en esta poesía ${ }^{20}$, pero también con la idea de una «humanidad» que, sin llegar a desaparecer por completo, se proyecta o se desplaza de los seres a las prendas de vestir.

Ya en las Greguerías de Ramón Gómez de la Serna, obra precursora de los distintos movimientos de vanguardia en España, puede observarse este frecuente proceso de personificación en el que las prendas de vestir «imitan», un poco por contagio, la humanidad de sus poseedores: «Los guantes adquieren manías y posturas propias, y en la soledad hacen gestos de los que han visto hacer a sus dueños» $»^{21}$. O, igualmente, sufren y padecen los mismos problemas de sus dueños: «Se asfixian unos gabanes a otros en la perchas llenas. Yo tengo un gabán que se me asfixió una vez, y no he podido volver a usarlo nunca» ${ }^{22}$.

Las personificaciones que aparecen en éstas y otras greguerías comparten con las imágenes de los primeros poemas ultraístas y creacionistas españoles el tono lúdico, deportivo e intrascendente que caracteriza la concepción que tienen estos poetas sobre la poesía, sobre el poeta mismo y sobre el arte en general. La cosificación del hombre y la personificación de los trajes y de las prendas de vestir se inserta en un contexto humorístico que relativiza y desmitifica todo lo que tenga que ver con la poesía y con el poeta. La superficialidad no es vista todavía como una falta o una ausencia de la que lamentarse, como lo será después, sino como una necesidad, que se convierte estéticamente en una proclama: «nada de esqueleto, nada de entrañas. Todo superficie $»^{23}$.

${ }^{17}$ DIEGO, Gerardo. «Panorama». En: Op. cit., I, p. 188.

${ }^{18}$ DIEGO, Gerardo. «Eco». En: Op. cit., I, p. 196.

${ }^{19}$ DIEGO, Gerardo. «Biografía incompleta». En: Op. cit., II, p. 307.

${ }^{20}$ La tendencia a la deshumanización y la imposibilidad de adoptar personajes o protagonistas humanos en estos poemas, unida a la idea de creación de mundos propios e independientes propia del creacionismo, conduce a una tendencia a la impersonalidad y a la despersonalización de los textos, que, en muchas ocasiones reflejan un mundo «creado», habitado por objetos y cosas que parecen haber cobrado vida. La poesía de Gerardo Diego de esta época ofrece numerosos ejemplos en este sentido: «Los verbos irregulares/ brincan como alegres escolares», «El violín descorre la cortina» o «La verja del jardín se ha cruzado de brazos». DIEGO, Gerardo. Op. cit., I, p. 106, 198 y 186.

${ }^{21}$ GÓMEZ DE LA SERNA, R. Greguerías. Cardona, R. (ed.). México: Rei, 1990, p. 101.

${ }^{22}$ Ibidem, p. 110.

${ }^{23}$ DIEGO, Gerardo. Op. cit., I, p. 101. 
Todas las asociaciones e imágenes anteriores, unidas a esa idea de la poesía como algo intrascendente o «sin dolor», convergen finalmente en la imagen o el motivo del traje o el cuerpo vacío o «vaciado», puesto que para escribir este tipo de poesía superficial, no surgida del corazón como la poesía anterior, se hace necesario extirpar este órgano:
Mi llave abre los trajes
y les extrae la carne interior
Corazón del vestido
Guardarropa y poesía sin dolor ${ }^{24}$.

El corazón es aquí, en realidad, sólo «carne interior», mientras que la palabra «corazón» se menciona como «corazón del vestido», y no del hombre $^{25}$.

Sin embargo, a medida que avanza el siglo y decae el entusiasmo por la modernidad, el progreso y los avances tecnológicos, la ausencia de corazón y la idea de superficialidad emocional que en un principio se veían como algo positivo y hasta necesario, se van convirtiendo en algo negativo de lo que lamentarse. El mismo Gerardo Diego, en la sección V de Biografía incompleta, de 1952, afirmará, con un tono ya más desencantado: «La abolición del pecho entre dos láminas de mica/ es el decreto más importante de nuestra pálida centuria», y la consecuencia de este acto de vaciado es precisamente, un vacío interior, un «vacío que vuela de chaleco en chaleco» ${ }^{26}$.

Es así como, en un segundo momento la imagen del cuerpo o del traje vacío empieza a asociarse con aspectos negativos como la falsedad y la falta de autenticidad, y con la insatisfacción que éstas producen:

Los sentimientos negativos, la falta de amor, el odio, son concebidos a menudo como atentados contra la propia humanidad. Tanto es así, que el poeta se siente entonces despojado de su carnalidad y convertido en materia orgánica, reificación en la que se simboliza la pérdida de identidad. (... ). Por eso, algunos poetas sustituyen al ser por el atuendo que visten, en un proceso metonímico que no es sino correlato expresivo de la falta de autenticidad ${ }^{27}$.

La identificación del hombre con la tela que lo cubre lo convierte indirectamente en un muñeco hecho de trapo, que incluso puede crearse por me-

\footnotetext{
${ }^{24}$ DIEGO, Gerardo. «Alegoría». En: Op. cit., I, p. 194.

${ }^{25}$ El mismo autor insiste en esta idea de poesía intrascendente y sin «opresión de pecho», en el «Poema a Violante», de la primera sección de Biografía incompleta (1925-1929), en el que, parodiando el soneto de Lope de Vega, se afirma, con una clara intención desmitificadora: «Un poema es un suspiro sin opresión de pecho/ Cuéntame tú los dientes y esta hecho». DIEGO, Gerardo. Op. cit., II, p. 282.

${ }^{26}$ DIEGO, Gerardo. «Grey». En: Op. cit., II, p. 355.

${ }^{27}$ MARTÍN CASAMITJANA, Rosa $\mathrm{M}^{\mathrm{a}}$. El humor en la poesía española de vanguardia. Madrid: Gredos, 1996, p. 223.
} 
dios artificiales, de los que se ha eliminado todo el proceso humano de la gestación: "Yo he visto a una mujer/ modelando a su hijo/ con una máquina de $\operatorname{coser} »^{28}$.

El traje, como sustituto del hombre, expresa muy bien además la idea de «imitación» y de disfraz de hombre, por oposición a la forma natural o real del cuerpo: «Mira Mira dónde está todo/ El color de los trajes que imitaba tan bien calidades de nuestra propia corteza» ${ }^{29}$.

Esta idea de disfraz, falseamiento u ocultación de lo interior que afectan tanto al hombre mismo y a su carnalidad como a sus verdaderos sentimientos encuentra una expresión muy coherente en la imagen de payaso, personaje que tiene una apariencia exterior alegre, potenciada además por el maquillaje y el vestido, pero que, sin embargo, esconde u oculta una tristeza interior. Esta imagen aparece, por ejemplo, en un poema ultraísta muy breve de Dámaso Alonso, titulado «A Juan Chabás»:

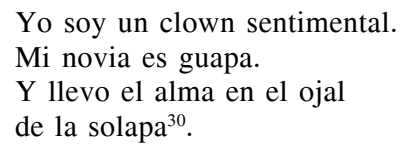

En el ojal de la solapa se lleva, generalmente, una flor, en las ocasiones festivas y destacadas. En este caso, la flor es el alma misma, que está fuera, externada, y no en el interior. La posible gravedad o solemnidad del tema manifestada en la idea del «clown sentimental», se ve aquí paliada por la sencillez casi infantil de las expresiones elegidas, que se acentúa con el humorismo de la rima consonante, tan frecuente en estos poemas lúdicos y paródicos. Sin embargo, al igual que la flor, esta forma externa del poema no es más que una apariencia, que oculta la verdadera naturaleza triste del payaso -y del poema, en este caso-, que se lleva oculta en el interior y no se deja ver. El tema del clown o el payaso será así uno de los temas predilectos de las vanguardias, tanto en los primeros momentos ultraístas y creacionistas por su alusión al mundo del circo y de lo funambulesco, como en el momento posterior del surrealismo. El mismo Lorca sentía predilección por los pierrots, como demuestran los distintos dibujos que de ellos realizó a lo largo de su vida. La imagen del clown también se asocia con los personajes protagonistas del cine mudo, esos «tontos» a los que precisamente Alberti dedica una de sus obras -Yo era un tonto, y lo que he visto me ha hecho dos tontoscomo, por ejemplo Charlot, por el que Lorca siente una gran admiración, como demuestra su texto «La muerte de la madre de Charlot», personaje que, en pa-

\footnotetext{
${ }^{28}$ DIEGO, Gerardo. «Fe». En: Op. cit., I, p. 122.

${ }^{29}$ DIEGO, Gerardo. «Hostilidad». En: Op. cit. II, p. 308.

30 DÍEZ DE REVENGA, F. J. Op. cit., p. 103.
} 
labras de Dionisio Cañas, «invitaba a meditar sobre una noble realidad: la tristeza íntima y la alegría exterior» ${ }^{31}$.

Es también en el momento surrealista cuando se intensifica la visión negativa que se tiene de la falta de autenticidad del hombre y de la imposibilidad de mostrar los verdaderos sentimientos y la verdadera identidad, y esta negatividad se proyecta sobre la sociedad en general, sobre sus imposiciones y su incapacidad de aceptar estilos de vida diferentes a los de un discurso único y homogeneizante. Es este tipo de sociedad intolerante e impositiva la que se critica en muchos poemas surrealistas de esta época, y la que dará lugar, en relación con el tema al que se refiere este trabajo, a personajes o protagonistas poéticos que se representan como seres vacíos, huecos y solitarios, enfrentados a una ciudad o una multitud impasible, como los que aparecen en muchos poemas de Rafael Alberti, Luis Cernuda y Federico García Lorca, alrededor de la década de los años 30. En ellos, el motivo del hombre o del traje vacío sigue apareciendo, aunque, además del cambio formal evidente de los poemas, éstos tendrán ahora un tono mucho más grave que el tono lúdico y festivo que tenían los poemas ultraístas y creacionistas, y la intención ya no será tanto la de ridiculizar y parodiar la literatura anterior, como la de criticar el sentimiento de falta y de desencanto general existente en el hombre y la sociedad contemporánea.

Con este sentido aparece el motivo, por ejemplo, en el poema «Remordimiento en traje de noche», de Luis Cernuda, perteneciente a Un río, un amor (1929), en el que se identifica, de manera explícita, al hombre con un «cuerpo vacío»:

Un hombre gris avanza por la calle de niebla; no lo sospecha nadie. Es un cuerpo vacío; Vacío como pampa, como mar, como viento, desiertos tan amargos bajo un cielo implacable.

Es el tiempo pasado, y sus alas ahora entre la sombra encuentran una pálida fuerza; es el remordimiento, que de noche, dudando, en secreto aproxima su sombra descuidada.

No estrechéis esa mano. La yedra altivamente ascenderá cubriendo los troncos del invierno. Invisible en la calma el hombre gris camina. ¿No sentís a los muertos? Mas la tierra está sorda ${ }^{32}$.

Nuevamente aparece aquí el juego entre lo interior y lo exterior y la personificación de sentimientos. El hombre gris que avanza por las calles podría

\footnotetext{
${ }^{31}$ CAÑAS, D. El poeta y la ciudad. Nueva York y los escritores hispanos. Madrid: Cátedra, 1994, p. 88 .

${ }^{32}$ CERNUDA, Luis. «Remordimiento en traje de noche». En: La realidad y el deseo. Madrid: Castalia, 1983, p. 115.
} 
verse como un correlato objetivo del estado emocional del hablante, ya que, como el título indica, el que está vestido y lleva ese traje no es el hombre como tal, sino el remordimiento. Al mismo tiempo, este personaje es «el tiempo pasado», y se caracteriza como una «sombra», tal vez una sombra de lo que fue o tuvo, y a la que ha quedado reducido en la actualidad el protagonista.

La misma idea y el mismo motivo aparecen recreados en el poema «El cuerpo deshabitado», perteneciente a Sobre los ángeles (1929), de Rafael Alberti. Además de en el título de este poema extenso dividido en secciones, la presencia del cuerpo deshabitado se encuentra también en su variante o formulación del traje vacío, que es también aquí un traje «deshabitado»: «Pasaba un traje/ deshabitado, hueco,/ cal muerta, entre los árboles» ${ }^{33}$, cuya razón de ser nos explica el primer fragmento del poema:

\section{1}

Yo te arrojé de mi cuerpo, yo, con un carbón ardiendo.

-Vete.

Madrugada.

La luz, muerta en las esquinas

y en las casas.

Los hombres y las mujeres

ya no estaban.

-Vete.

Quedó mi cuerpo vacío, negro saco, a la ventana.

Se fue.

Se fue, doblando las calles.

Mi cuerpo anduvo, sin nadie ${ }^{34}$.

Al igual que en el poema de Cernuda, este cuerpo vacío es la consecuencia presente de algo anterior, y si ya no se habla aquí de sombra de un pasado, sí de la soledad y el aislamiento provocados por una ruptura personal o amorosa, sugerida repetitivamente a lo largo del poema: «te arrojé de mi cuerpo», «Vete», «ya no estaban», «Se fue» y «sin nadie». Es, por tanto, la idea de pérdida la que subyace en todos estos casos, idea que resalta la oposición antes/ahora, que se convierte en una valoración positivo/negativo. Lo mismo ocurre en el poema «1910», de Poeta en Nueva York, de Lorca, escrito también en 1929. En este poema se rememora de forma nostálgica el paraíso de la infancia y de la inocencia perdida, haciendo hincapié en «aquellos ojos míos» que no habían visto, y que por lo tanto no conocían todavía el dolor y la muerte, sino cosas puras, positivas e infantiles. El poema termina con un

${ }^{33}$ ALBERTI, Rafael. Sobre los ángeles. Yo era un tonto y lo que he visto me ha hecho dos tontos. Morris, B. (ed.). Madrid: Cátedra, 1989, p. 74.

${ }^{34}$ Ibidem, p. 73. 
regreso al momento presente del hablante y a la inefabilidad provocada precisamente por los horrores presenciados, por el desamor y por la muerte:

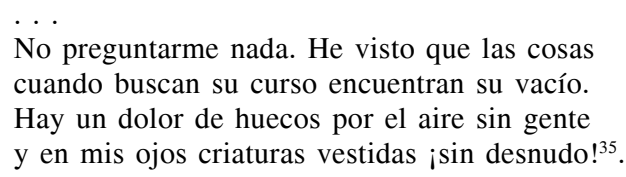

Como bien señala María Clementa Millán respecto a esta imagen: «Lo más auténtico del hombre ha desaparecido, ' $i$ sin desnudo!', y sólo queda lo engañoso de su vestimenta» ${ }^{36}$. Aunque en este poema en concreto el vacío se refiere al vacío de las cosas y de los otros, existen también en este poemario numerosas referencias al vacío o al hueco personal, que es una de las ideas centrales del libro. Hay, precisamente, un poema titulado «Nocturno del hueco», en el que se afirma ya de manera explícita: "Yo./ Mi hueco traspasado con las axilas rotas./ (...) /Mi hueco sin ti...» ${ }^{37}$.

En los tres poemas anteriores, por tanto, el tema o la idea del hombre vacío y del hueco se relacionan con la idea de la pérdida. Ya no se trata aquí, como ocurría en la poesía de la primera vanguardia, de que el hombre representado en los poemas no tenga corazón o no deba tenerlo por motivos estéticos y de que éste se rebaje al asociarlo con los elementos de la modernidad, sino que lo tenía pero lo ha perdido por la acción devastadora del tiempo y de la vida en sociedad, ambos factores responsables, según la concepción surrealista, de la corrupción del hombre.

El antes, momento temporal u original de la dicha, se hace así también un allí, con lo que la oposición se traslada a terrenos espaciales. El allí del pasado suele identificarse con la infancia perdida, como en el caso de Lorca, o con un antes en el que existía una relación amorosa, como en los otros dos poetas. Se trata, en definitiva de la idea de un lugar mitificado, un paraíso que se ha perdido, y cuya pérdida condena al hombre, desterrado o expulsado de ese edén de felicidad, a la soledad de una vida en el paraje hostil de una ciudad inhumana e insensible. El motivo del hombre o del traje vacío se relaciona, de esta forma, con el motivo o el tópico literario de la ciudad moderna, cuyo tratamiento también evoluciona desde la aceptación y la defensa optimista y eufórica del ultraísmo y el creacionismo hasta el rechazo del surrealismo, que ve en la ciudad un lugar artificial y antinatural para la vida del hombre.

A pesar de que esta ciudad moderna estaba presente ya en los poemas anteriores, su presencia era una presencia indirecta o fragmentaria, sugerida más

\footnotetext{
${ }^{35}$ GARCÍA LORCA, F. Op. cit., p. 113.

${ }^{36}$ Ibidem, p. 242.

${ }^{37}$ GARCÍA LORCA, F. «Nocturno del hueco, II». En: Op. cit., p. 188.
} 
bien sinecdóquicamente a través de los elementos modernos que la componen, que son los que interesa destacar: medios de comunicación y de transporte, elementos del mundo circense y del espectáculo, y objetos «modernos» y tecnológicos de todo tipo. En la poesía surrealista, sin embargo, la ciudad, es la ubicación y el escenario real en el que se desarrollan muchos de estos poemas y adquiere una relevancia especial. Por un lado, como ya mencioné, estas ciudades modernas son vistas en este momento histórico como la causa de la pérdida de ideales y valores de la civilización occidental y como un elemento destructor y alienador de los seres humanos, aunque en muchos casos, como afirma Dionisio Cañas, no sean más que un dispositivo o un catalizador que condensa o focaliza unos sentimientos de rechazo y de defensa de los poetas y su sensación de pérdida a distintos niveles ${ }^{38}$. Por otro lado, esta visión negativa de la ciudad también tiene que ver con cuestiones estéticas y, en ese sentido, es necesariamente heredera de una tradición literaria y cultural. Creo que, sin coincidir exactamente en todos sus aspectos, y salvando las distancias ideológicas y temporales, la presencia y la caracterización de esta ciudad moderna surrealista podría relacionarse con el topos de la ciudad muerta del simbolismo, que tiene su origen, como señala Miguel Ángel Lozano, en la novela de Georges Rodenbach, Bruges-la-Morte - Brujas muerta-, que se publicó en París en 1892 y que creó una moda literaria que tuvo numerosos seguidores ${ }^{39}$. Aunque el tema de la ciudad de la muerte ya había sido tratado por autores como Edgar Allan Poe — «The City in the Sea»—o D'Anunzio - La citta morta, será en la obra de Rodenbach donde se configure este tópico de una manera más sistemática, en todos sus elementos: el día es gris, el hombre pasea por ella al atardecer o el anochecer, la estación del año es la de otoño o invierno, las calles están desiertas o transitadas por figuras aisladas y concretas, las casas están siempre cerradas y el silencio sólo se ve alterado por el sonido de las campanas. La caracterización negativa de la ciudad en esta novela proviene también de su identificación con el alma de la esposa muerta del protagonista, que elige en su viudez esta ciudad melancólica precisamente porque en todos sus detalles cree reconocer el rostro y la presencia de su mujer desaparecida.

Aunque muy diferente de este tratamiento simbolista, los poemas surrealistas retoman algunos elementos del tópico de la ciudad muerta, pues es, como el mismo Miguel Ángel Lozano afirma, un motivo estético que responde a la psicología de la derrota, que reaparecerá, de manera sorprendente, en la literatura española de los años treinta, con algunas modificaciones, en un momento en el que la industrialización y la modernidad han avanzado de manera notable en la sociedad española ${ }^{40}$.

${ }^{38}$ CAÑAS, Dionisio. Op. cit., p. 18.

${ }^{39}$ LOZANO MARCO, M. A. «Una visión simbolista del espacio urbano: la ciudad muerta». En: Rovira, J. C; Navarro, J. R. (eds.). Literatura y espacio urbano, Alicante: Caja de Ahorros del Mediterráneo: Fundación Cultural, 1994, p. 60.

${ }^{40}$ Ibidem, p. 65 y 73. 
En esta caracterización negativa de la ciudad como lugar de desolación y de muerte, y en la adaptación que realizan los poetas españoles en relación con el hombre vacío no puede olvidarse tampoco la importancia que tienen obras y títulos posteriores y significativos como The Waste Land (1922) y The Hollow Men (1925), de T. S. Eliot. En estas obras, como indica Francisco Ruiz Soriano, el hombre ya aparecía descrito como: «un mero cuerpo hueco, vacío de ideales espirituales producto de sus crisis personales y existenciales, con un tremendo sentimiento de angustia y desolación interior e inserto dentro del ambiente de un nuevo espacio urbano: el de la ciudad moderna, caracterizada como tierra estéril y muerta» ${ }^{41}$.

En estos y otros antecedentes, el espacio ya es visto como un lugar de abandono y desolación. En los poemas surrealistas, sin embargo, esta sensación de soledad y aislamiento no viene dada por la ausencia de los otros, sino, precisamente por la presencia de una muchedumbre colectiva e insensible con la que no es posible la comunicación, lo que provoca el sentimiento de aislamiento y marginalidad. El espacio que se habita es así un espacio alterno y marginal, un reducto propio, que es también un tiempo paralelo, en el que los sujetos aparecen como desterrados, tanto literal como metafóricamente.

Esta idea de la marginalidad en relación con la incomunicación con los otros puede verse claramente en los poemas mencionados. El personaje del poema de Cernuda «Remordimiento...», visto más arriba, pertenece a otro mundo, al mundo de lo marginal, que se representa en la «noche» misma de la que va vestido, por oposición al día, y no es visto ni oído por nadie: «no lo sospecha nadie», camina «invisible» en la calma, y además «la tierra está sorda». Esta idea de soledad e incomunicación es constante en el Cernuda de Un río, un amor. El protagonista de los poemas es siempre un hombre solo, fatigado, desdibujado, que camina por espacios desiertos. En el poema titulado significativamente «Destierro», el protagonista del que habla el poema «lleva su destino a solas», mientras todos «acaso duermen», en una ciudad de «puertas bien cerradas» ${ }^{42}$. También en el Alberti de Sobre los ángeles, la ciudad es una ciudad ajena e insensible. En un poema de título igualmente revelador, «Paraíso perdido», se habla de «Ciudades sin respuesta,/ ríos sin habla, cumbres/ sin ecos, mares mudos» ${ }^{43}$. Y en «El ángel desconocido», de este mismo libro, se une la idea de la ciudad hostil y muda con la de la pérdida de un pasado o situación anterior, ideas que se cifran, precisamente, en términos de un cambio de vestuario, que simboliza aquí la caída o la conversión de ángel a hombre:

\footnotetext{
${ }^{41}$ RUIZ SORIANO, F. Op. cit., p. 43.

${ }^{42}$ CERNUDA, Luis. La realidad y el deseo. Flys, M. (ed.). Madrid: Castalia, 1983, p. 119.

${ }^{43}$ ALBERTI, Rafael, Op. cit., p. 65.
} 


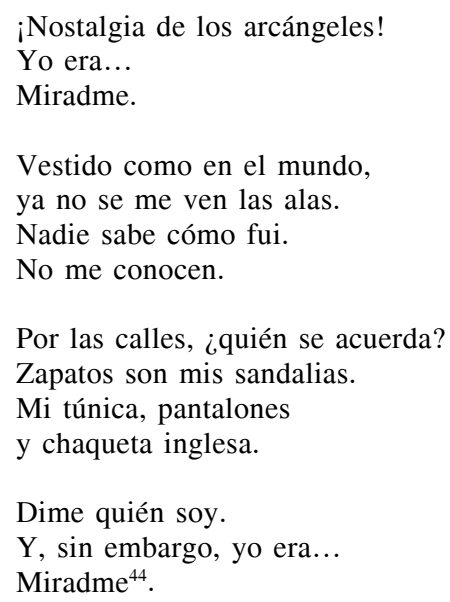

Estos dos últimos versos resumen perfectamente, a mi entender, la idea y el sentimiento contenido en este motivo del traje en los poemas de esta época. El «Yo era», seguido de puntos suspensivos, manifiesta la nostalgia por lo perdido, por esa condición angélica o por ese lugar sagrado y edénico, mientras que el «Miradme» final, que sintetiza otros lamentos y peticiones anteriores — «No me conocen», «Dime quién soy»— supone esa exhortación a los otros, a esa mayoría anónima, ciega y sorda, que no reconoce, al tiempo que manifiesta la necesidad esencial del hombre de ser visto, de ser percibido.

Pero este reclamo de un lugar en el mundo no será escuchado por esa ciudad hostil, que se va convirtiendo en un lugar cada vez más amenazante y destructor y que, coherente con la idea de paraíso en que se metaforizaba el tiempo y el espacio perdido, se acaba asociando de manera directa ya con la idea del infierno ${ }^{45}$.

Ante esta situación externa, y contrariamente a lo que pasaba en los poemas de la primera vanguardia, al hombre sólo le queda el refugio de su inte-

\footnotetext{
${ }^{44}$ Ibidem, p. 72.

${ }^{45}$ Por ejemplo, Alberti en verso final del poema «Muerte y juicio», de Sobre los ángeles, escribe: «Para ir al infierno no hace falta cambiar de sitio ni de postura». ALBERTI, Rafael. Op. cit., p. 137. En relación con esta caracterización negativa de la ciudad, Brian Morris en su artículo «Satans's Offerings: Cities in Modern Literature», estudia la imagen de la ciudad de Nueva York que aparece en algunos poemas españoles de la época, generalmente asociada con un infierno o un cementerio y con la sensación de aislamiento, de soledad y de muerte en vida, por la alienación que padecen los poetas. Morris analiza autores y obras como Versos viejos de Francisco Vighi; Urbe (1927), de César M. Arconada; y La ciudad automática (1933) de Julio Camba. Cit. por CAÑAS, Dionisio. Op. cit., p. 147. Por su parte, Elena Castro también llama la atención sobre esta presencia del infierno en Alberti y remite para su estudio al libro de DALE MAY, Bárbara. El dilema de la nostalgia en la poesía de Rafael Alberti. Berna: Peter Lang, 1978.
} 
rioridad, que es ahora el lugar donde puede albergarse el auténtico ser. Esto provoca, necesariamente, un desdoblamiento o una duplicación entre lo interior y lo exterior, entre la realidad o la autenticidad individual y la imagen social o colectiva que se ofrece a los otros. Esta duplicidad o alteridad se entiende en muchas ocasiones como la muerte de alguna de las dos facetas del hombre, que no puede manifestarse ni expresarse, o como una especie de suicidio interior, como ocurre en un poema de Emilio Prados:

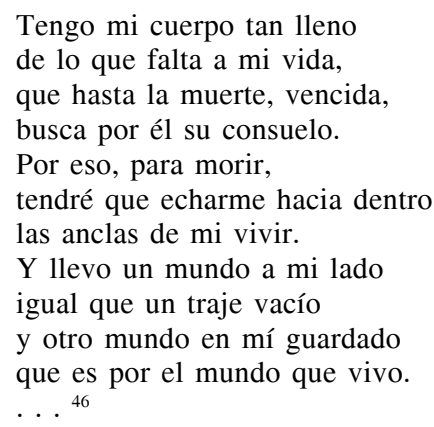

En este poema, la abundancia está en el interior y la carencia en el exterior, creando así dos planos o dos mundos separados, el del cuerpo y el del traje vacío, que responde a una oposición entre vida y muerte, respectivamente. Esta oposición provoca una paradoja en su formulación, puesto que una de las partes está llena con la falta de la otra; el cuerpo está «lleno de lo que falta», mientras que la muerte va a buscar lo que no tiene fuera en el interior del hombre, lo que podría entenderse también como una especie de destierro o suicidio interior.

El motivo del traje y del cuerpo vacío se asocia así a la idea de los muertos vivientes, hombres sonámbulos o zombies, que deambulan por el mundo y por las grandes ciudades. Y es que la ubicación de muchos de estos poemas en ciudades modernas permite, además, la incorporación del movimiento, en la acción de caminar o desplazarse de sus protagonistas. El hombre vacío de estos poemas es un ser que camina, o que más bien deambula sin rumbo por estas ciudades, en busca, tal vez, de sí mismo, de su propia identidad o su unidad perdida. Como señala Elena Castro, comentando precisamente el poema «Walking around», de Residencia en la tierra, de Neruda: «la voz poética, el auténtico 'yo', acaba convertido en una sombra que anda tras de sí mismo, de sus huellas; es decir, de su cuerpo vacío que avanza por el mundo en un simulacro de existencia ${ }^{47}$. Este simulacro de existencia queda perfectamente

\footnotetext{
${ }^{46}$ «Tres canciones», I, de Mínima muerte (1944). En: RAMONEDA, Arturo (ed.). Antología poética de la generación del 27, Madrid: Castalia, 1990, p. 301.

${ }^{47}$ CASTRO, Elena. La subversión del espacio poético en el surrealismo español. Madrid, Visor, 2008, p. 68.
} 
reflejado en la aparición de numerosos dobles o duplicaciones de los protagonistas o hablantes poéticos, que pueden representarse de formas variadas, desde la sombras o los muertos vivientes, ya mencionados, hasta los ángeles, los muñecos, los espantapájaros o las estatuas, caracterizaciones, todas ellas, con las que el motivo del traje vacío guarda una estrecha relación. Tanto la sombra como el traje vacío son, además, formas comunes de la expresión de la fragmentación o la disolución de la conciencia individual, no exclusivas de este momento histórico ni tampoco de la poesía, pues también aparecen en la pintura $^{48}$ y en el cine. En la película surrealista «Un perro andaluz», se utiliza este motivo del traje como duplicación falseada del hombre, en una escena metonímica en la que «se ponen todos los elementos de un traje sobre la cama y poco a poco emana de él la figura de un joven, alter ego del protagonista» ${ }^{49}$.

Dentro del ámbito poético, esta idea de duplicación puede verse, por ejemplo, en el poema de Pedro Salinas titulado precisamente «La otra», especie de fábula o narración, de Fábula y signo (1931), en el que una mujer, que habla con su sombra, decide morir en un día determinado, a partir del cual está muerta por dentro, pero viva por fuera y para los demás:

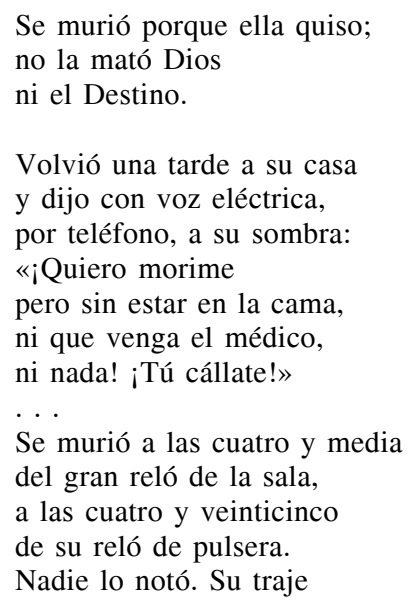

${ }^{48} \mathrm{La}$ autora relaciona el tema de la sombra con la pintura surrealista de la época, concretamente con algunos cuadros de la pintora Remedios Varo: «Este desdoblamiento en sombra y cuerpo, típico del universo cernudiano, es también recogido por otros surrealistas como Rafael Alberti o la pintora Remedios Varo, quien años después, en su cuadro Fenómeno (1962), pinta una sombra caminando seguida por su reflejo, que en este caso es la persona, en un desdoblamiento opuesto al que acabamos de ver en el poema de Cernuda. Y en Despedida, Varo presenta lo que parece ser la despedida entre dos amantes cuyos cuerpos se alejan pero cuyas esencias, simbolizadas en sus sombras, se mantienen abrazadas en el lugar de su encuentro.» CASTRO, Elena. Op. cit., pp. 68-69.

${ }^{49}$ Ibidem, pp. 71-72. 


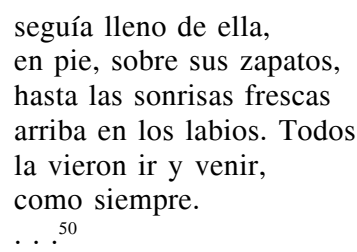

Se hace hincapié aquí en cómo el traje de esta protagonista femenina «seguía lleno de ella», aunque está en realidad vacío, puesto que, igual que en el poema de Emilio Prados, está lleno de muerte, o lleno de nada.

Otra forma de duplicación se encuentra, por ejemplo, en el ángel muerto que aparece en el poema ya mencionado «Paraíso perdido», de Sobre los ángeles de Alberti, en que este ángel que va detrás del protagonista poético, que también deambula sin rumbo por «la nada del mundo» buscando supuestamente a la persona amada y perdida, es comparable con la sombra que aparecía en los poemas de Cernuda. Nuevamente, el entorno, la ciudad, el mundo entero, incluido el ángel mismo al que se increpa, permanecen impasibles y sin respuesta:
A través de los siglos, por la nada del mundo, yo, sin sueño, buscándote.
Tras de mí, imperceptible, sin rozarme los hombros, mi ángel muerto, vigía.
¿Adónde el Paraíso, sombra, tú que has estado? Pregunta con silencio.
Ciudades sin respuesta, ríos sin habla, cumbres sin ecos, mares mudos. $\ldots 0^{51}$

Del muerto, de la sombra o del ángel en la representación de al alteridad puede pasarse también, por ejemplo, al espantapájaros, solución perfecta para este motivo, que reúne la idea del traje vacío y la cosificación del hombre, puesto que es precisamente o literalmente eso: un traje vacío sin nada dentro, que evoca la figura humana, pero que refleja perfectamente la idea de deshumanización o vaciado.

\footnotetext{
${ }^{50}$ SALINAS, Pedro. «La otra». En: Aventura poética. Stixrude, D. (ed.). Madrid: Cátedra, 1996, pp. 93-94.

${ }^{51}$ ALBERTI, Rafael. Op. cit., p. 65.
} 
En el poema titulado «Espantapájaros», de Rafael Alberti, perteneciente a Sermones y moradas (1935), se intensifica la idea del hombre agobiado por la angustia, que deambula solo en un espacio hostil. Aunque no se mencione explícitamente, los hombres pobladores de ese mundo son nuevamente reducidos a trajes, asociación que evidencia el título del poema, trajes que, a su vez, aparecen personificados en un doble proceso ya familiar a este motivo:

Ya en mi alma pesaban de tal modo los muertos futuros que no podía andar ni un solo paso sin que las piedras revelaran sus entrañas. ¿Qué gritan y defienden esos trajes retorcidos por las exhalaciones?

Sangran ojos de mulos cruzados de escalofríos.

...

¿Adónde ir con las ansias de los que han de morirse? $\ldots{ }^{52}$

Otra variante de los hombres muertos o vacíos la constituyen también las estatuas, que igual que en los casos anteriores, suponen, tanto la cosificación del hombre, como la animación de los objetos. Estas estatuas, cercanas a los espantapájaros y a los muñecos de trapo, aparecen, por ejemplo, en el poema «Niña ahogada en el pozo», de Poeta en Nueva York, convirtiéndose en testigos mudos de la tragedia del ahogamiento infantil, que sin embargo, y a diferencia de los hombres masa o muchedumbre, poseen la capacidad de sentir:

Las estatuas sufren con los ojos por la oscuridad de los ataúdes pero sufren mucho más por el agua que no desemboca.

... que no desemboca ${ }^{53}$.

En todas estas variantes, que tienen como telón de fondo la ciudad moderna, la sensación de inadaptación y de vacío se va intensificando, y se pasa de la indiferencia y la ignorancia de los otros a la hostilidad y la agresividad de un único ente personificado que enajena, agrede y mutila al hombre. Los protagonistas de estos poemas aparecen ahora como seres incompletos y mutilados también en su exterior, en una imagen propia del surrealismo.

En «Decidme anoche», de Un río, un amor, de Cernuda, es el dolor el que se personifica como un «incesante fantasma con mirada de estío/ Fantasma que desfila prisionero de nadie/ falto de voz, de manos, apariencia sin vida» ${ }^{54}$. Aquí, a la condición de «apariencia», común a otros poemas y a otras imágenes, se suma la ausencia de partes físicas: «falto de voz, de manos», idea que se repite, de manera más intensa en el poema en prosa, «En medio de la multitud», de Los placeres prohibidos, (1931) del mismo autor:

\footnotetext{
${ }^{52}$ ALBERTI, Rafael. «Espantapájaros». En: Ramoneda, Arturo (ed.). Op.. cit., p. 334.

${ }^{53}$ GARCÍA LORCA, F. Op. cit., p. 178.

${ }^{54}$ CERNUDA, Luis. La realidad y el deseo. Flys, M. (ed.) Madrid: Castalia, 1983, pp. 121-122.
} 


\begin{abstract}
Vacío, anduve sin rumbo por la ciudad. Gentes extrañas pasaban a mi lado sin verme. (...) Anduve más y más. No sentía mis pies. Quise cogerlos en mi mano, y no hallé mis manos; quise gritar y no hallé mi voz. La niebla me envolvía. Me pesaba la vida como un remordimiento; quise arrojarla de mí. Más era imposible, porque estaba muerto y andaba entre los muertos ${ }^{55}$.
\end{abstract}

Esta mutilación alcanza su mayor eficacia y expresividad cuando se une a la imagen de la muñeca o del maniquí, también muy del gusto surrealista. Como señala Elena Castro: «la figura del maniquí es una obsesión surrealista por ser la que mejor expresa la confusión de lo humano con lo objetual. (...) la figura del maniquí surge de la intersección de dos grandes temas: la cosificación del ser humano y la mutilación $»^{56}$. Esta confluencia de cosificación, personificación y mutilación puede verse, por ejemplo, en el poema surrealista «Muñecas», de Espadas como labios (1932), de Vicente Aleixandre. En él los protagonistas no son personas ni mujeres, sino muñecas, «cartón amable», «cartón de luna», al mismo tiempo que las muñecas se personifican, pues «cantan con los codos». El conjunto es un retrato de seres fragmentados, que combinan lo natural con lo artificial, «carne madera o liquen»; seres confusos y mutilados — «Muchachas con un pecho», «carne rota en pedazos como herrumbre», «Gigantes de placer sin cabeza»-, que nuevamente aparecen descritos o identificados con alguna prenda de vestir: «Muchachas delantales» ${ }^{57}$.

Después de todas estas asociaciones del hombre vacío con el muerto interior, la sombra, las estatuas, el espantapájaros o los maniquíes y las muñecas, este motivo, en lo que tiene de lamento y crítica ante las imposiciones sociales y la falsedad que provocan, parece derivarse o resolverse, tanto dentro todavía del movimiento surrealista como en poemas posteriores, mediante la adopción de la animalidad, como recurso, tal vez, o como forma de recuperar la parte auténtica, orgánica y vital del ser humano. El hablante poético se identificará, entonces, con las bestias. Como señala Elena Castro, comentando algunos pasajes de Lorca y de Aleixandre: «Los animales se idealizan frecuentemente y representan las virtudes que les faltan a los hombres. (...) En un mundo en el que el hombre ha dejado de ser el rey del universo, parece lógico que los animales se igualen a los humanos e incluso en ocasiones están más humanizados que éstos ${ }^{58}{ }^{5}$. Aunque la imagen del hombre animal, bestia o fiera, es, como la misma autora señala, una imagen ambivalente, puesto que además de la idea de recuperación de la parte natural e inocente del hombre, los animales también son vistos en su fiereza como

\footnotetext{
${ }^{55}$ CERNUDA, Luis. Antología. Capote Benot, J. M. (ed.). México: Rei, 1990, p. 104.

${ }^{56}$ CASTRO, Elena. Op. cit., p. 147.

${ }^{57}$ ALEIXANDRE, Vicente. Espadas como labios. La destrucción o el amor. Cano, J. L. (ed.). Madrid: Castalia, 1989, pp. 73-74.

${ }^{58}$ CASTRO, Elena. Op. cit., p. 160.
} 
símbolo de destrucción. En este sentido, citaré, nada más, para terminar, dos ejemplos, uno de Vicente Aleixandre, en su primera etapa, y otro de Miguel Hernández, ajeno ya al surrealismo y más cercano, en este caso, a la poesía social.

Aleixandre, participando también, como sus contemporáneos, de la visión negativa y crítica de la ciudad vista mítica o simbólicamente como la maldad, reacciona contra el vestido y las vestiduras en general, que son falseadoras de la verdad natural del hombre, que es su desnudo. A lo largo de sus obras iniciales, por tanto, Aleixandre opondrá sistemáticamente el vestido, que se ve como algo negativo, e incluso llega a compararse con la muerte - los hombres vestidos están «dormidos» o «muertos»- al desnudo, que es lo que se persigue y se anhela. El poema titulado precisamente «El desnudo», de La destrucción o el amor (1935), termina con esta afirmación:

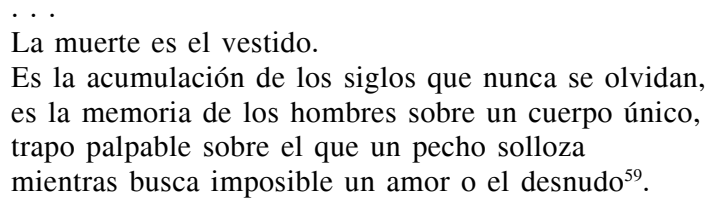

El vestido es muerte porque es falseamiento, que es también aquí constructo, acumulación histórica de una máscara que se repite. Recuperar al hombre auténtico es, por tanto, quitarse esa acumulación, en el acto simbólico de desnudarse. Esta misma idea aparece en el poema «El hambre», de Miguel Hernández, del poemario El hombre acecha (1939). El título de este poemario, en el que puede verse la frase de Plauto, adoptada después por Tomás Hobbes «el hombre acecha al hombre», me parece muy significativo. Porque es precisamente la idea del otro, de la masa, y la de las necesidades y los instintos humanos más primarios, como por ejemplo el hambre, lo que hace al hombre despojarse de todas sus máscaras y sus imposiciones, para recuperar su aspecto vital más elemental: la animalidad:

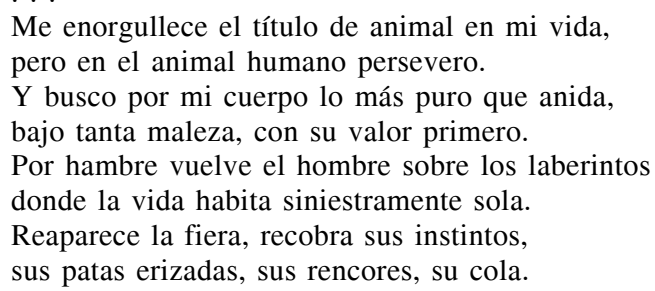

\footnotetext{
${ }^{59}$ ALEIXANDRE, Vicente. Op. cit., p. 226. En relación con el tema del desnudo y los trajes, así como sobre el tratamiento de la animalidad en Vicente Aleixandre, véase BOUSOÑO, Carlos. La poesía de Vicente Aleixandre. Madrid: Gredos, 1977.
} 


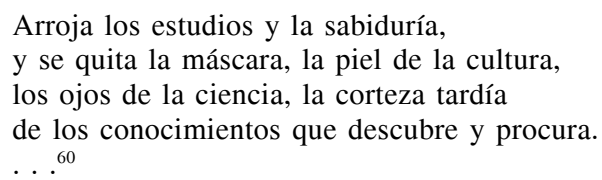

Muy lejos ya de la racionalización y el cerebralismo de los primeros poemas de vanguardia, que defendían la superficialidad y la asepsia sentimental, y también de la profundidad y la intensidad surrealista, el hombre queda reducido ahora a lo básico, a lo primario o a lo carnal, instintos en los que puede identificarse con los animales. Esta animalidad, vista como positiva, es también una búsqueda que necesita, al igual que en Aleixandre, del desnudo, del acto de eliminación de lo exterior, si ya no traje directamente, sí «máscara», «piel» $\mathrm{y}$ «corteza»; «maleza» que hay que eliminar para llegar, al fin, a «lo más puro», al «valor primero», en un juego de oposiciones permanente entre lo exterior y lo interior.

Después de todo lo analizado en páginas anteriores, puede decirse que la imagen del traje o del cuerpo vacío, lejos de ser un hallazgo casual en la poesía española de principios de siglo, es un motivo o un tópico recurrente, que se utiliza de manera sistemática por distintos autores y en distintas obras. La importancia y la vitalidad de este motivo se pone de manifiesto, además, en su carácter intertextual e interdisciplinar, puesto que, como se ha visto, no afecta nada más a la poesía, sino que también aparece en el cine y en la pintura, con las que la poesía de vanguardia guarda una estrecha relación. El motivo, además, no se configura como algo estático o fijo, sino que es más bien un elemento dinámico y vivo que evoluciona y se transforma, en el uso personal y particular que los poetas hacen de él en sus adaptaciones. En esta evolución se incluye también, en este caso, un cambio de valoración en cuanto a lo que el motivo significa y representa para cada época. Así como en los primeros momentos vanguardistas -ultraísmo y creacionismo - se valora positivamente la superficialidad y la falta de interioridad, que se ven como alejamiento del sentimentalismo de la poesía anterior y de su símbolos — corazón-, en un momento posterior —el del surrealismo y la poesía siguienteel motivo adquirirá connotaciones negativas, por su percepción de la superficialidad como falsedad y apariencia, en oposición a la autenticidad y la individualidad interior. La ciudad moderna, a la que se asocia inevitablemente este motivo por el momento histórico en el que aparece, afectado directamente por la idea de progreso, también sufre un cambio de perspectiva, que equivale, igualmente, al paso del entusiasmo inicial al rechazo final, siendo vista como responsable o como símbolo de la sociedad masiva, intolerante y mutiladora del ser humano. La imposibilidad de encontrarse a uno mismo o de mostrar-

${ }^{60}$ HERNÁNDEZ, Miguel. «El hambre, II». En: El hombre acecha. Cancionero y romancero de ausencias. Luis, L. de; Urrutia, J. (eds.). Madrid: Cátedra, 1998, p. 136. 
se abiertamente en su individualidad provoca la sensación de fragmentación y disociación, que se refleja en los textos mediante el tema literario del doble y las duplicaciones. El propio traje vacío ya es o podría verse como una duplicación falseada del hombre real, pero también la imagen se asocia con otros dobles como, por ejemplo, el clown o el payaso, la sombra, el muerto viviente, el ángel, el muñeco y los maniquíes, el espantapájaros y la estatua. Finalmente, aunque la imagen del hombre enajenado que deambula por la ciudad seguirá existiendo en la poesía española contemporánea, el tema del traje vacío o del vacío interior evoluciona, en su dolorida expresión, hacia las imágenes del desnudo, por un lado, como aspecto positivo del hombre, y por otro, hacia el contagio con la imagen del hombre como animal o como fiera, tanto en su aspecto positivo de regreso a lo natural y a la esencia, como en su aspecto negativo de fiereza y falta de solidaridad.

\section{REFERENCIAS BIBLIOGRÁFICAS}

ALBERTI, R. Sobre los ángeles. Yo era un tonto y lo que he visto me ha hecho dos tontos. Morris, B. (ed.). Madrid: Cátedra, 1989.

ALEIXANDRE, V. Espadas como labios. La destrucción o el amor. Cano, J.L. (ed.). Madrid: Castalia, 1989.

ALONSO, D.; LAIIN ENTRALGO, P. «Quevedo. Expresión y talante poético». En: Rico, Francisco (ed.). Historia y crítica de la literatura española, Siglos de Oro: Barroco. Barcelona: Ariel, 1983, pp. 593-603.

BOUSOÑO, C. La poesía de Vicente Aleixandre. Madrid: Gredos, 1977 (1956).

CANO BALLESTA, J. L. La poesía española entre pureza y revolución (1920-1936). Madrid: Siglo XXI, 1972.

CAÑAS, D. El poeta y la ciudad. Nueva York y los escritores hispanos. Madrid: Cátedra, 1994.

CARNERO, G. «El mito de la ciudad en la época vanguardista». En: Rovira, J. C.; Navarro, J. R. (eds.). Literatura y espacio urbano. Alicante: Caja de Ahorros del Mediterráneo, Fundación Cultural, 1994, pp. 84-93.

CASTRO, E. La subversión del espacio poético en el surrealismo español. Madrid: Visor, 2008.

CERNUDA, L. La realidad y el deseo. Flys, M. (ed.). Madrid: Castalia, 1983.

-. Antología. Capote Benot, J. M. (ed.). México: Rei, 1990.

CIPLIJAUSKAITÉ, B. De signos y significaciones. I. Juegos con la Vanguardia: poetas del 27. Barcelona: Anthropos, 1999.

DIEGO, G. Obra completa. Poesía I y II. Díez de Revenga, F.J. (ed.).. Madrid: Aguilar, 1989.

DÍEZ DE REVENGA, F. J. La poesía de vanguardia. Madrid: Ediciones del Laberinto, 2001.

DURAND, G. Las estructuras antropológicas de lo imaginario. Madrid: Taurus, 1982.

EVOLA, J. Metafísica del sexo. Palma de Mallorca: José de Olañeta, 1997.

GARCÍA LORCA, F. Poeta en Nueva York. Millán, M.C. (ed.). Madrid: Cátedra, 1989.

GÓMEZ DE LA SERNA, R. Greguerías. Cardona, R. (ed.). México: Rei, 1990.

HERNÁNDEZ, Mario. «Imagen en Cometa errante». Anales de Filología Hispánica, 1989, $\mathrm{n}^{\circ} 8$, pp. 47-57.

HERNÁNDEZ, Miguel. El hombre acecha. Cancionero y romancero de ausencias. Luis, L. de; Urrutia, J. (eds.). Madrid: Cátedra, 1998. 
HINTERHAUSER, H. Fin de siglo. Figuras y mitos. Madrid: Taurus, 1980.

LOZANO MARCO, M. A. «Una visión simbolista del espacio urbano: la ciudad muerta». En: Rovira, J.C.; Navarro, J. R. (eds.). Literatura y espacio urbano. Alicante: Caja de Ahorros del Mediterráneo: Fundación Cultural, 1994, pp. 60-73.

MARTÍN CASAMITJANA, R. M. El humor en la poesía española de vanguardia. Madrid: Gredos, 1996.

MAY, B. D. El dilema de la nostalgia en la poesía de Rafael Alberti. Berna: Peter Lang, 1978.

MORRIS, B. «Satans's Offerings: Cities in Modern Literature». Renaissance and Modern Studies. 1984, $\mathrm{n}^{\circ}$ 28, pp. 87-103.

—. El surrealismo y España, 1920-1936. Madrid: Espasa-Calpe, 2000 (1972).

NAUPERT, C. (comp.). Tematología y comparatismo literario. Madrid: Arco/Libros, 2003.

RAMONEDA, A. (ed.). Antología poética de la Generación del 27. Madrid: Castalia, 1990.

ROVIRA, J. C.;. NAVARRO, J. R. (eds.). Literatura y espacio urbano. Alicante: Caja de Ahorros del Mediterráneo, Fundación Cultural, 1994.

ROSALES, L. y OROZCO DÍAZ, E. «Quevedo. Temas y Tópicos». En Rico, Francisco (ed.). Historia y crítica de la literatura española, Siglos de Oro: Barroco. Barcelona: Ariel, 1983, pp. 669-676.

RUIZ SORIANO, F. «Eliot, Cernuda y Alberti: la ciudad vacía». Cuadernos Hispanoamericanos, 1995, $\mathrm{n}^{\circ}$ 539-540, pp. 43-54.

SALINAS, P. Aventura poética. Stixrude, D. (ed.). Madrid: Cátedra, 1996.

SÁNCHEZ VIDAL, A. «Extrañamiento e identidad de 'su majestad el yo' al 'éxtasis de los objetos'». En García de la Concha, Víctor (ed.). Surrealismo, Madrid: Taurus, 1982, pp. 50-73.

Fecha de recepción: 1 de junio de 2009

Fecha de aceptación: 15 de diciembre de 2009 